\title{
Influence of substrate on structural, morphological and optical properties of ZnO films grown by SILAR method
}

\author{
F N JIMÉNEZ-GARCÍA ${ }^{\mathrm{a}, \mathrm{b}, *}$, C L LONDOÑO-CALDERÓN ${ }^{\mathrm{a}}$, D G ESPINOSA-ARBELÁEZ ${ }^{\mathrm{c}}$, \\ A DEL REAL ${ }^{\mathrm{c}}$ and M E RODRÍGUEZ-GARCÍA ${ }^{\mathrm{c}}$ \\ a Departamento de Física y Matemáticas, Universidad Autónoma de Manizales, Antigua Estación del Ferrocarril, \\ Manizales, Caldas, Colombia \\ ${ }^{\mathrm{b}}$ Departamento de Física y Química, Universidad Nacional de Colombia, Sede Manizales, Campus la Nubia, \\ Manizales, Caldas, Colombia \\ ${ }^{\mathrm{c}}$ Departamento de Nanotecnología, Centro de Física Aplicada y Tecnología Avanzada, \\ Universidad Nacional Autónoma de México, Blv Juriquilla 3001, Juriquilla, Querétaro, C.P. 76230, México
}

MS received 22 May 2013; revised 24 August 2013

\begin{abstract}
ZnO films were obtained by successive ionic layer adsorption and reaction (SILAR) method from four different substrates: glass microslides, corning glass, quartz and silicon with and without oxide layer. For films deposition, a precursor solution of $\mathrm{ZnSO}_{4}$ was used, complexed with ammonium hydroxide. Prior to the film deposition, wettability of the substrates was analysed using a CCD camera. It was found that the Si without the oxide layer substrate shows hydrophobic behaviour, which makes the films less adherent and not uniform, while in the other substrates, the behaviour was optimal for the growing process. ZnO films grown on glass microslides, corning glass, quartz and $\mathrm{Si}$ with oxide layer were characterized using $\mathrm{X}$-ray diffraction (XRD), scanning electron microscopy (SEM) and UV-Vis techniques. According to the XRD patterns, the films were polycrystalline, with hexagonal wurtzite structure and the patterns mentioned showed significant differences in crystallite sizes, microstrain and texture coefficient with respect to the employed substrates. The morphology of the $\mathrm{ZnO}$ films constituted by rice-like and flower-like structures shows differences in form and size depending on the substrate. The UV-Vis spectroscopy results show that the substrate did not influence the band gap energy value obtained from films.
\end{abstract}

Keywords. ZnO; substrates; X-ray diffraction; scanning electron microscopy; SILAR.

\section{Introduction}

Zinc oxide $(\mathrm{ZnO})$ in powder, in bulk and in thin films has been widely studied due to the combination of its unique properties such as non-toxicity, good electrical properties, transparence in visible range, direct band gap, hardness, piezoelectric behaviour, chemical stability, abundance in nature and low cost. Among several metal oxide semiconductors, $\mathrm{ZnO}$ nanostructure has been identified as a potential material for future device applications like solar cells (Keis et al 2002), photo detectors (Liang et al 2001), transparent ultraviolet protection films (Saito 2002), gas sensor elements (Pizzini et al 1989) and light emitting devices (Srivastava et al 2007), among others.

Different methods have been used for $\mathrm{ZnO}$ thin films synthesis, including pulsed laser deposition (PLD) (Cao et al 2007), thermal evaporation (Shen et al 2005), spray pyrolysis (Saito 2002) and metal-organic chemical vapour deposition (MOCVD) (Egerton et al 2005). Chemical

\footnotetext{
*Author for correspondence (francy@autonoma.edu.co)
}

bath deposition (CBD) and successive ion layer absorption and reaction (SILAR) have been used by several authors (Ortega-López et al 2003; Gao et al 2004; Shinde et al 2005; Vargas-Hernández 2008) to produce good $\mathrm{ZnO}$ structures. These methods have attracted special interest because of their simplicity, low cost and capability to achieve large area coatings. They have also been used to obtain a large variety of semiconductor materials, as have been reported by Pawar (2011).

The research results on fabrication and application of $\mathrm{ZnO}$ films have proved the fact that their morphology plays a key role in their application for specific fields. Until now, a special wide variety of $\mathrm{ZnO}$ morphologies (complex structured films) have been grown using physical or chemical methods. Some studies related to morphology of $\mathrm{ZnO}$ thin films have been published and some of the reported structures are needles, tubes, flowers, stars, bars and strings, among others (Kim et al 2004; Shinde et al 2005; Villanueva et al 2006).

Although there are some studies related to the influence of the substrate temperatures on the structural properties of $\mathrm{ZnO}$ thin films, the real effect on the structural 
properties of the films related to the type of substrate has not been identified (Shan et al 2004; Rambu et al 2012). Recent results of $\mathrm{ZnO}$ thin films obtained by thermal oxidation of metallic $\mathrm{Zn}$ suggest a dependence of the nature of the substrate and the temperature of oxidation on the structural and electrical properties (Rambu et al 2012). The roles and effects of additives, the different condition of growth and the substrate types are established in order to develop ZnO films with high quality for devices with good performance. For example, the substrate in the emitting device structure has been found to be important on the surface plasmon (Cheng et al 2008). Besides, the degree of $\left(\begin{array}{lll}0 & 0 & 2\end{array}\right)$ plane orientation of $\mathrm{ZnO}$ films is directly related to the piezoelectric property, which is an important issue on related devices of surface acoustic wave (SAW) (Bai 2010).

The aim of this paper is to study the effect of four different and common types of substrate on the structural, morphological and optical properties of $\mathrm{ZnO}$ films grown by the SILAR method. The wettability study was conducted to determine the hydrophilic characteristics of substrates. XRD was used to observe changes within the crystalline structure, and SEM to identify how morphology changes with the substrate. Finally, UV-Vis was used to find whether the band gap changes as a result of different substrates.

\section{Experimental}

ZnO films were deposited by the SILAR process on four different substrates: glass microscope slides, corning glass, silicon (Bromont-Canada, $5 \mathrm{ohm}-\mathrm{cm}, 500 \mu \mathrm{m}$ thickness) with oxide layer and quartz. Substrates were treated before deposition. For this, first, they were boiled in diluted sulfuric acid (1:10 v/v) for $1 \mathrm{~h}$, then, ultrasonically rinsed in ethanol and acetone for $30 \mathrm{~min}$, and finally stored in double-distilled water until use. The corning substrates were not treated in sulfuric acid to avoid chemical attack. Silicon substrates were treated as mentioned before, one of them was then submerged in a solution of diluted hydrofluoric acid ( $\left.\mathrm{HF}: \mathrm{H}_{2} \mathrm{O}=5: 100\right)$ for $1 \mathrm{~min}$ to remove chemical and native oxides and to study its wettability characteristics.

The SILAR process used to obtain the films includes alternating by dipping the substrate in $\mathrm{Zn}^{2+}$ source at room temperature and in hot water near the boiling point. Aqueous zinc sulfate solution $(0 \cdot 1 \mathrm{M})$ was used as source of $\mathrm{Zn}$ ions, which was made alkaline by addition of concentrated ammonia hydroxide (28\%) in molar ratio of $1: 10$.

Glass substrates were successively immersed for $2 \mathrm{~s}$ in alkaline zinc sulfate solution so as to get zinc complex adsorbed onto the substrate. After $2 \mathrm{~s}$ of immersion of substrate into the hot $\mathrm{H}_{2} \mathrm{O}$, the reaction occurs at substrate surface to form $\mathrm{ZnO}$. One hundred deposition cycles were conducted to obtain a visibly detectable and lustrous $\mathrm{ZnO}$ layer. After the growth process, the samples were air dried for $1 \mathrm{~h}$ and annealed in air at $200{ }^{\circ} \mathrm{C}$ for $2 \mathrm{~h}$.

The experimental procedure was carried out by employing a stepper motor that provided a constant velocity for the sample immersion within the chemical baths. The system allowed the simultaneous growth of four samples under the same conditions. A commonly used procedure (Mitra et al 1998; Mitra and Khan 2006) has been automated to obtain the films; a detailed description of this experimental procedure to obtain $\mathrm{ZnO}$ films has been described in a previous paper (Jiménez-García et al 2010).

The contact angle was measured by using a CCD camera for each substrate in order to study the wettability of the substrates. The substrate was placed on a movable stage in front of the CCD camera. Drops of precursor solution were put onto the substrate using a vertical syringe; its volume was approximately $20 \mu \mathrm{L}$. Images of the drops were recorded with the CCD camera, on establishing the contrast, magnification and focal were set as well. The experiments were performed at room temperature $\left(23^{\circ} \mathrm{C}\right)$.

The structural characterization of $\mathrm{ZnO}$ films was carried out by XRD patterns, obtained in the range of the diffraction angle between 15 and $80^{\circ}$, with $\operatorname{CuK} \alpha$ radiation by using a Siemens D5000 diffractometer $(\lambda=1.5406 \AA)$. An SEM model JEOL JSM-6060 LV (Japan) with energy of $15 \mathrm{kV}$ was used to study the morphology of the samples. The chemical composition (semi-quantitative) of the thin films was obtained by means of an INCA Oxford-X-ray energy dispersive spectroscopy (EDS) to $20 \mathrm{kV}$. A spectrometer (double beam Perkin Elmer) was used to obtain the optical transmittance spectra. The measurements were done between 300 and $500 \mathrm{~nm}(\lambda)$. The same substrates (glasses and quartz) were used as a reference. All measurements were done at room temperature.

\section{Results and discussion}

\subsection{Wettability analysis}

Surface wettability is an important parameter to be controlled and modified because it involves the interaction between liquids and solids. Some applications include photo-activated self-cleaning and anti-fogging materials. The surface adsorption and hydrophilic/hydrophobic properties have to be carefully controlled to achieve optimal functionality (Hashimoto et al 2005). The wetting behaviour is characterized by the value of the contact angle $\theta$, a macroscopic parameter. If the wettability of the system increases, $\theta$ decreases and the interaction becomes hydrophilic, and vice versa. The contact angle is an important parameter in surface science and its measurement provides a simple and reliable technique for the interpretation of surface energies (Lokhande 2003).

The images obtained by the CCD camera serve to measure the contact angle of each substrate. These results 

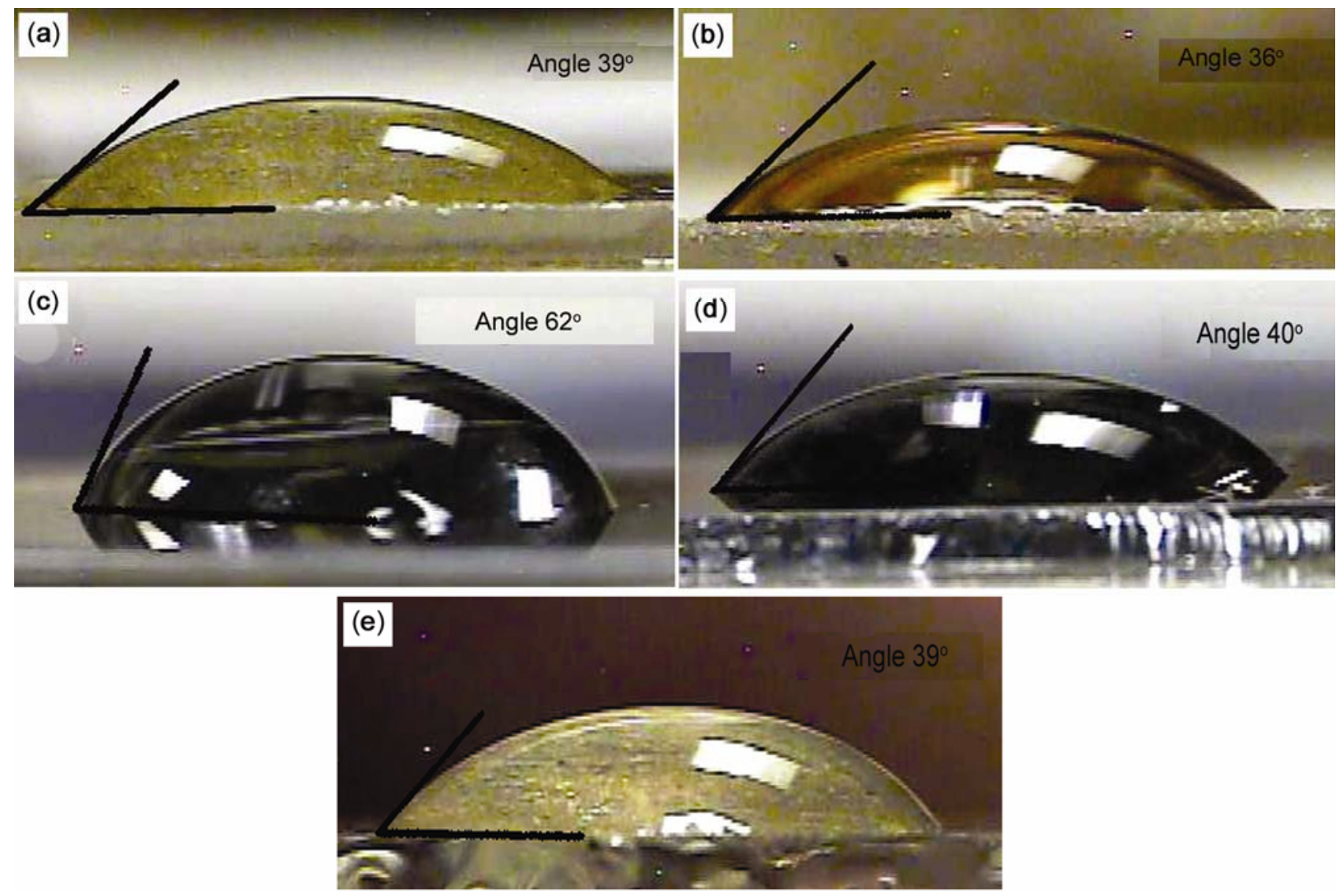

Figure 1. Images to determine the contact angle for (a) corning glass, (b) quartz, (c) Si without oxide layer, (d) Si with oxide layer and (e) glass microslides.

are shown in figure 1. Taking into account the contact angles measured for each substrate, its wettability can be arranged in a top-down order, namely, quartz, commercial glass, corning glass, $\mathrm{Si}-\mathrm{SiO}_{2}$ and $\mathrm{Si}$. The Si substrate was the most hydrophobic of all the employed substrates, as it was expected due to the pickling done with $\mathrm{HF}$ (Hermansson et al 1991). The incidence of this hydrophobicity on film characteristics was that films grown over them were not uniform and easy to remove. Some authors have reported that to link hydrophobic surfaces, it is necessary to apply pressure on them (Ljungberg et al 1993). Since the employed process of growth does not require any pressure, this could explain why the films are not uniform and have bad adherence. For this reason, film grown on the Si substrate was not included in this study. Besides, the contact angle did not change significantly for the other four substrates, meaning that wettability was almost the same for the glasses and for the $\mathrm{Si}-\mathrm{SiO}_{2}$ substrates.

\subsection{ZnO film formation}

The mechanism of $\mathrm{ZnO}$ film formation by SILAR method can be explained as follows. The $0 \cdot 1 \mathrm{M} \mathrm{ZnSO}$ solution used as a source of zinc was made alkaline with the addition of aqueous ammonia under constant stirring. Initially, when aqueous ammonia solution was added to the zinc sulfate solution, the ionic product of $\mathrm{Zn}(\mathrm{OH})_{2}$ exceeds the solubility product and the solution becomes milky turbid due to the formation of $\mathrm{Zn}(\mathrm{OH})_{2}$. This can be explained by the following reaction

$$
\mathrm{ZnSO}_{4}+2 \mathrm{NH}_{4} \mathrm{OH} \Rightarrow \mathrm{Zn}(\mathrm{OH})_{2}+2 \mathrm{NH}_{4}^{+}+\mathrm{SO}_{4}^{-2} \text {. }
$$

However, further addition of excess ammonia solution reduces $\mathrm{Zn}^{2+}$ ion by producing the complex ions of the type $\mathrm{Zn}\left(\mathrm{NH}_{3}\right)_{4}^{2+}$, which is the most stable complex (Sillen and Martell 1971), avoids precipitation and makes solution clear and transparent. This can be explained by the following reaction

$$
\mathrm{Zn}(\mathrm{OH})_{2}+4 \mathrm{NH}_{4}^{+} \Rightarrow \mathrm{Zn}\left(\mathrm{NH}_{3}\right)_{4}^{2+}+2 \mathrm{H}_{2} \mathrm{O}+2 \mathrm{H}^{+} .
$$

When substrates are immersed in the obtained solution, these zinc complex ions get adsorbed on the substrates due to attractive force between ions in the solution and the surface of the substrates. These forces may be cohesive or Van der Waals forces or chemical attractive forces (Pathan and Lokhande 2004). 
Table 1. Crystallographic, morphological and optical information for $\mathrm{ZnO}$ films grown on different substrates.

\begin{tabular}{|c|c|c|c|c|c|}
\hline \multirow{3}{*}{$\begin{array}{l}\text { Substrates } \\
\text { Glass microslides }\end{array}$} & \multirow{3}{*}{$\begin{array}{c}\begin{array}{c}\text { Crystallite } \\
\text { sizes (nm) }\end{array} \\
67\end{array}$} & \multirow{3}{*}{$\begin{array}{c}\text { Microstrains } \\
(\%)\end{array}$} & \multirow{3}{*}{$\begin{array}{c}\begin{array}{c}\text { Texture } \\
\text { coefficient }\end{array} \\
2 \cdot 27\end{array}$} & \multirow{2}{*}{\multicolumn{2}{|c|}{$\begin{array}{c}\text { Grain sizes }(\mu \mathrm{m}) \\
\text { Average* }^{*}\end{array}$}} \\
\hline & & & & & \\
\hline & & & & $0 \cdot 59$ & $0 \cdot 10$ \\
\hline Corning glass & 64 & $0 \cdot 23$ & $1 \cdot 89$ & $0 \cdot 34$ & 0.09 \\
\hline $\mathrm{Si}-\mathrm{SiO}_{2}$ & 44 & $0 \cdot 33$ & $1 \cdot 73$ & $0 \cdot 61$ & $0 \cdot 10$ \\
\hline Quartz & 30 & $0 \cdot 24$ & $1 \cdot 15$ & $0 \cdot 60$ & $0 \cdot 11$ \\
\hline
\end{tabular}

*Standard deviation of the average grain size.

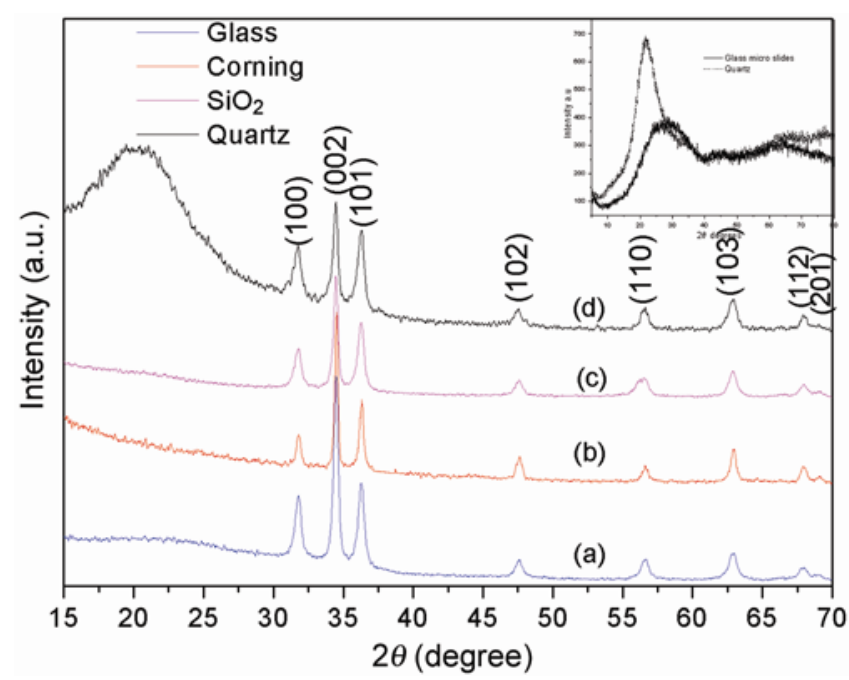

Figure 2. X-ray diffraction pattern for as-deposited $\mathrm{ZnO}$ films grown on different substrates: (a) glass microslides, (b) corning glass, (c) $\mathrm{SiO}_{2}$ and (d) quartz.

The substrates are then immersed in hot $\mathrm{H}_{2} \mathrm{O}$ to convert the zinc complex into $\mathrm{ZnO}$ by the reaction

$$
\mathrm{Zn}\left(\mathrm{NH}_{3}\right)_{4}^{2+}+2 \mathrm{OH}^{-} \Rightarrow \mathrm{ZnO}+4 \mathrm{NH}_{3}+2 \mathrm{H}_{2} \mathrm{O} \text {. }
$$

\subsection{X-ray diffraction study}

Figure 2 shows the XRD patterns of the $\mathrm{ZnO}$ films grown on the four substrates described earlier. According to the patterns, all samples were polycrystalline. All peaks can be indexed to hexagonal wurtzite structure of $\mathrm{ZnO}$ (JCPDF no. 00036 1451). The preferential growth direction was along the $c$-axis, with planes oriented in the $\left[\begin{array}{lll}0 & 0 & 2\end{array}\right]$ direction. These patterns also serve to calculate the following lattice parameters: $a=(3 \cdot 251 \pm 0.003) \AA$ and $c=(5 \cdot 200 \pm 0.003) \AA$, which coincide with those reported in the literature (Kihara and Donnay 1985). The percentage difference between the lattice parameters for each film grown on different substrates is not higher than $0.08 \%$. The results suggest that the unit cell dimensions do not suffer significant modifications with respect to the used substrate for the film grown. From the XRD patterns, it is possible to conclude that the preferential growth orientation and the unit cell size are independent of the employed substrate.

The full width at half maximum (FWHM) could be modelled as a convolution of a Gaussian and Lorentzian profile (Voigt function), where the Gaussian component is due to microstrain and the Lorentzian component is due to crystallite size (Mittermeijer and Welzel 2008). Table 1 shows the crystallite average sizes obtained from the diffraction peak $\left(\begin{array}{lll}0 & 02\end{array}\right)$ using the Sherrer's formula $\left(\lambda / \beta_{\mathrm{L}} \cos \theta\right)$, where $\lambda$ is the wavelength of the $K_{\alpha}$ line, $\beta_{\mathrm{L}}$ is the FWHM from Lorentzian function obtained from the XRD pattern deconvolution and $\theta$ is the Bragg angle (Robert et al 2008). These results show a strong dependence between the crystallite average size and the employed substrate for the film grown. It is interesting to note that the film grown on glass microslides substrate exhibits better definition on diffraction peaks. This film has the biggest crystallite size.

The microstrain $(\varepsilon)$ calculated for the films is shown in table 1. The microstain was evaluated for the $c$-axis direction from the equation $\left(\varepsilon=\beta_{\mathrm{G}} / 4 \tan \theta\right)$, where $\beta_{\mathrm{G}}$ is the FWHM from the Gaussian function obtained from the XRD pattern deconvolution (Mittermeijer and Welzel 2008). These results lead us to infer that there is a strong dependence between the substrate and microstrain grain in deposited films. This dependence is due to the substrate nature since all films were obtained at the same conditions. The substrates of corning and quartz have a higher purity than the substrates of commercial glass as well as a low thermal expansion coefficient (Bach and Krause 2005). During the growth process, films are under constant change in temperature when the substrate passes from one solution to another. The substrates of corning and quartz suffer less thermal stress due to their lower thermal expansion coefficient. This means that films grown on these substrates exhibit less microstrain.

Some authors state that although the initial formation of $\mathrm{SiO}_{2}$ on the $\mathrm{Si}$ substrate is not homogeneous, it becomes ordered to minimize the stress-deformation energy (Moholkar et al 2007). Besides, Si has a low thermal expansion coefficient. Both characteristics show that films growing on the $\mathrm{Si} / \mathrm{SiO}_{2}$ substrate have less microstrain than the ones grown in glasses. These results suggest 


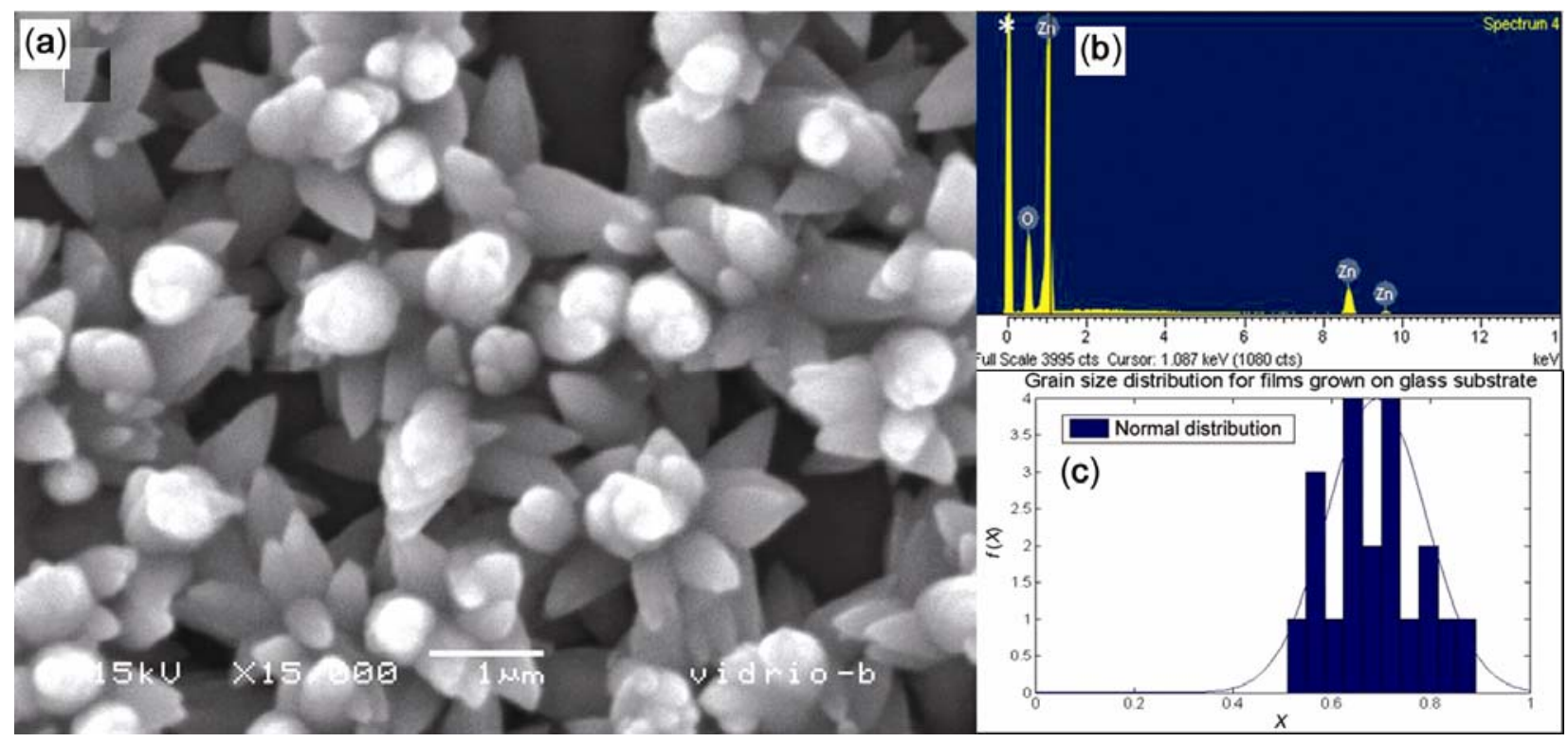

Figure 3. (a) Rice-like structure for films grown on glass microslides substrate, (b) EDS spectrum for film grown on glass microslide substrate and (c) histogram for the grain size distribution for film grown on glass microslide substrate.

that the microstrains are mainly generated by residual stress between surface substrate and film.

Films grown on quartz substrate exhibit one peak between 18 and $25^{\circ}$ and those grown on glass microslides show one width peak between 20 and $25^{\circ}$. These peaks are characteristics of each substrate, as it is shown in figure 2 (inset), where the XRD patterns for these substrates are shown.

As it is well known, by using the XRD pattern, it is possible to evaluate the preference orientation of the thin films with the evaluation of the texture coefficient (TC) (Cerofolini et al 1997), as it is shown in (4)

$$
T C_{h k l}=\frac{I_{h k l} / I_{0 h k l}}{1 / n \sum I_{h k l} / I_{0 h k l}},
$$

where $I$ is the measure of intensity of each peak, $I_{0}$ the standard intensity of each peak from the ASTM corresponding powder and $n$ the number of the considered diffractions peaks. From this definition, it is clear that when there is a higher deviation of TC of the unit, preferential orientation is higher too.

Table 1 shows the TC for peak $\left(\begin{array}{lll}0 & 0 & 2\end{array}\right)$ estimated for each substrate. From these results, it can be inferred that the preferential growth of the films is related to the substrates. The films were grown with a preferential orientation and with higher crystallite sizes on glass microscopy slides substrate, indicating that these films have good crystalline characteristics, although the purity and cost of these substrates are lower than the others. The crystallite size related to the $\left(\begin{array}{lll}0 & 0 & 2\end{array}\right)$ diffraction peak is bigger for films grown on glass microscopy slides because its TC is highest. Although this substrate has higher microstrain than the others, the glass microscopy slide allows more stability and promotes the growth of planes in a specific direction.

The crystallite size is smaller in $\mathrm{Si} / \mathrm{SiO}_{2}$ substrate than in glasses, probably because those films have to replicate the order of $\mathrm{SiO}_{2}$ formed over the $\mathrm{Si}$ substrate. Also, it can be due to the difference between the lattice parameters of substrate and film, so that there is less probability of duplication.

\subsection{Semiquantitative EDS analysis}

The semiquantitative composition of $\mathrm{ZnO}$ films was determined by EDS spectroscopy by measuring at different sites of the samples. Figures 3(b)-6(b) show the EDS spectra measured in one general region of each sample, the peak labeled ' $*$ ' originates from the Au layer that was applied to the films for the SEM measurement. Weight and atomic percentages obtained for $\mathrm{Zn}$ and $\mathrm{O}$ of each film are shown in table 2. From these results, it is possible to say that films are oxygen rich and there are no considerable differences with respect to the substrate. It means that the chemical composition and the stoichiometry are apparently independent of the substrate nature.

\subsection{Morphology study}

The growth of $\mathrm{ZnO}$ structure is greatly affected by chemical species in the interfacial zone. In particular, the degree of supersaturation of $\mathrm{Zn}(\mathrm{OH})_{2}$ in the interfacial zone and the adsorption of organic/inorganic species on 


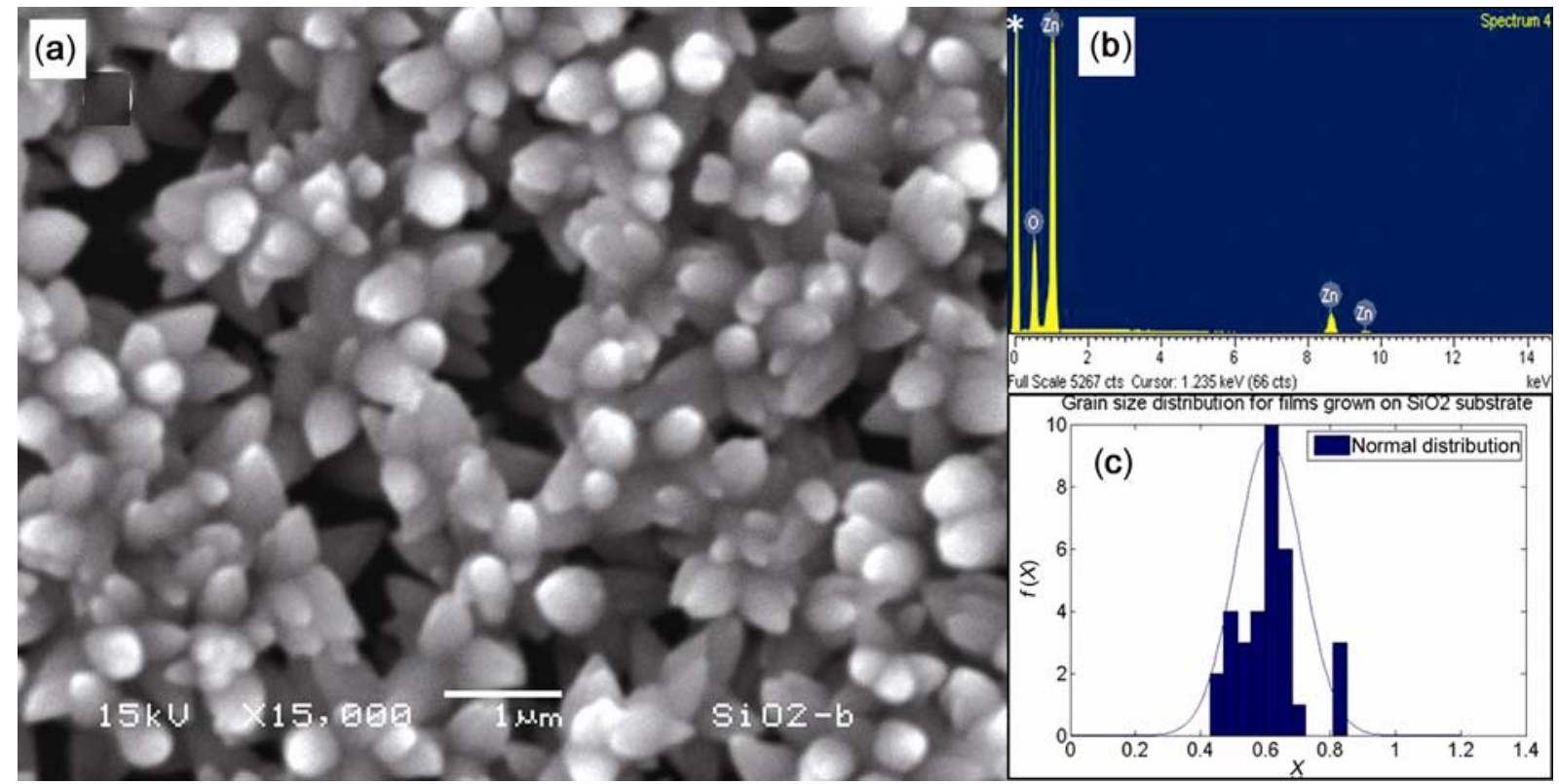

Figure 4. (a) Rice-like structure for films grown on $\mathrm{Si}-\mathrm{SiO}_{2}$ substrate, (b) EDS spectrum for film grown on $\mathrm{Si}-\mathrm{SiO}_{2}$ substrate and (c) histogram for the grain size distribution for film grown on $\mathrm{Si}-\mathrm{SiO}_{2}$ substrate.

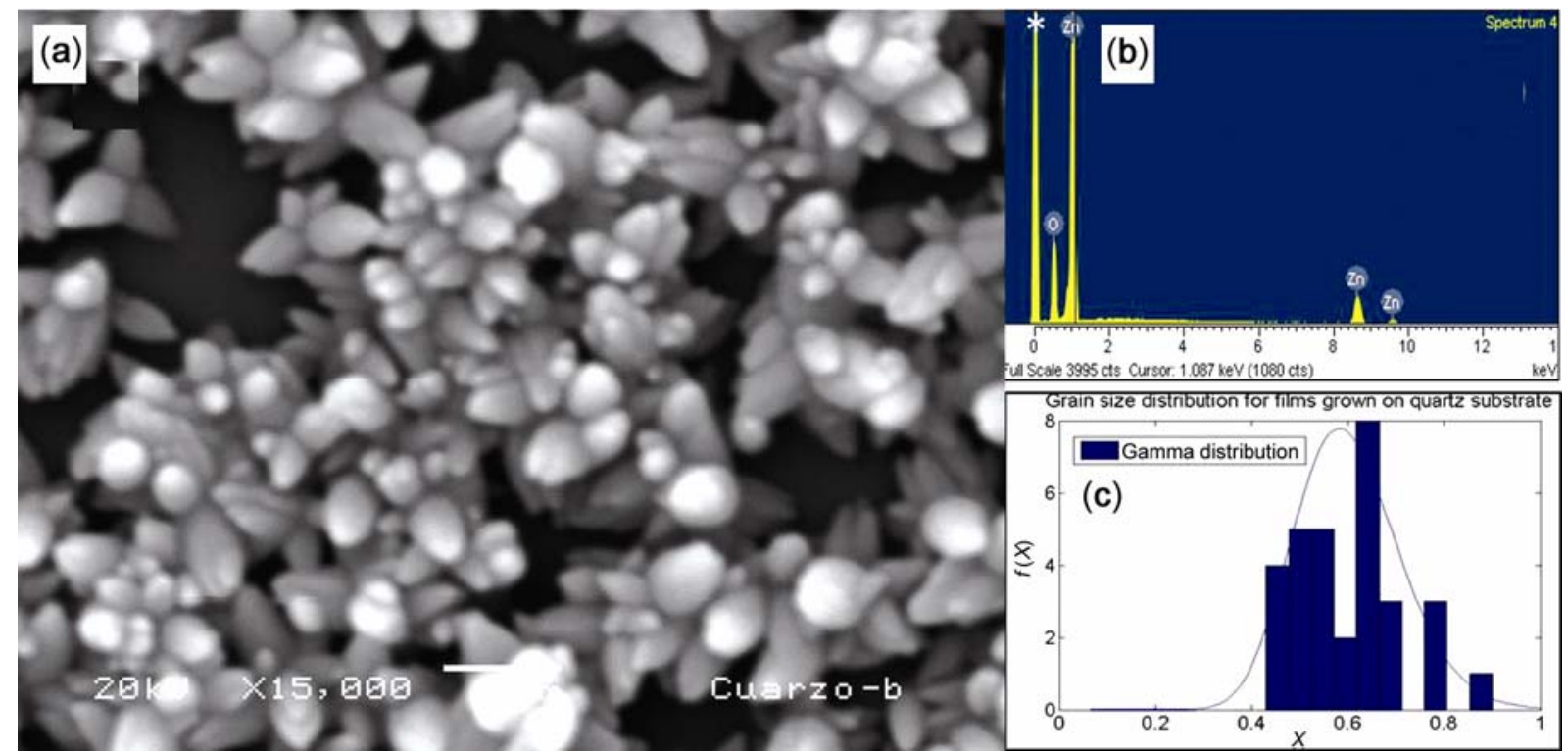

Figure 5. (a) Rice-like structure for films grown on quartz substrate, (b) EDS spectrum for film grown on quartz substrate and (c) histogram for the grain size distribution for film grown on quartz substrate.

the surface of $\mathrm{ZnO}$ are key factors influencing the nucleation and the film growth.

The SEM images of the $\mathrm{ZnO}$ films grown on all substrates are shown in figures 3(a)-6(a) and in figures 7(a)-(d).

The films grown on all substrates used in this study have a random distribution of flowers and a basic distribution of spindle-like structures or rice-like branches. The basic morphology of the films is related to the rice-like branches, having a circular cross section and tapering towards each end with a length of approximately
$1 \mu \mathrm{m}$. The films are porous as indicated by the SEM images.

The grain size was statistically analysed taking into account the larger diameters of the grains in each film. Normality tests employing modified Shapiro Wilk test and goodness of fit tests for the Gamma distributions employing Kolmogorov-Smirnov test were made. For the films grown in glass and $\mathrm{Si}-\mathrm{SiO}_{2}$ substrates, it is observed a normal distribution of grain sizes, while for quartz and corning substrates a Gamma distribution was obtained. 


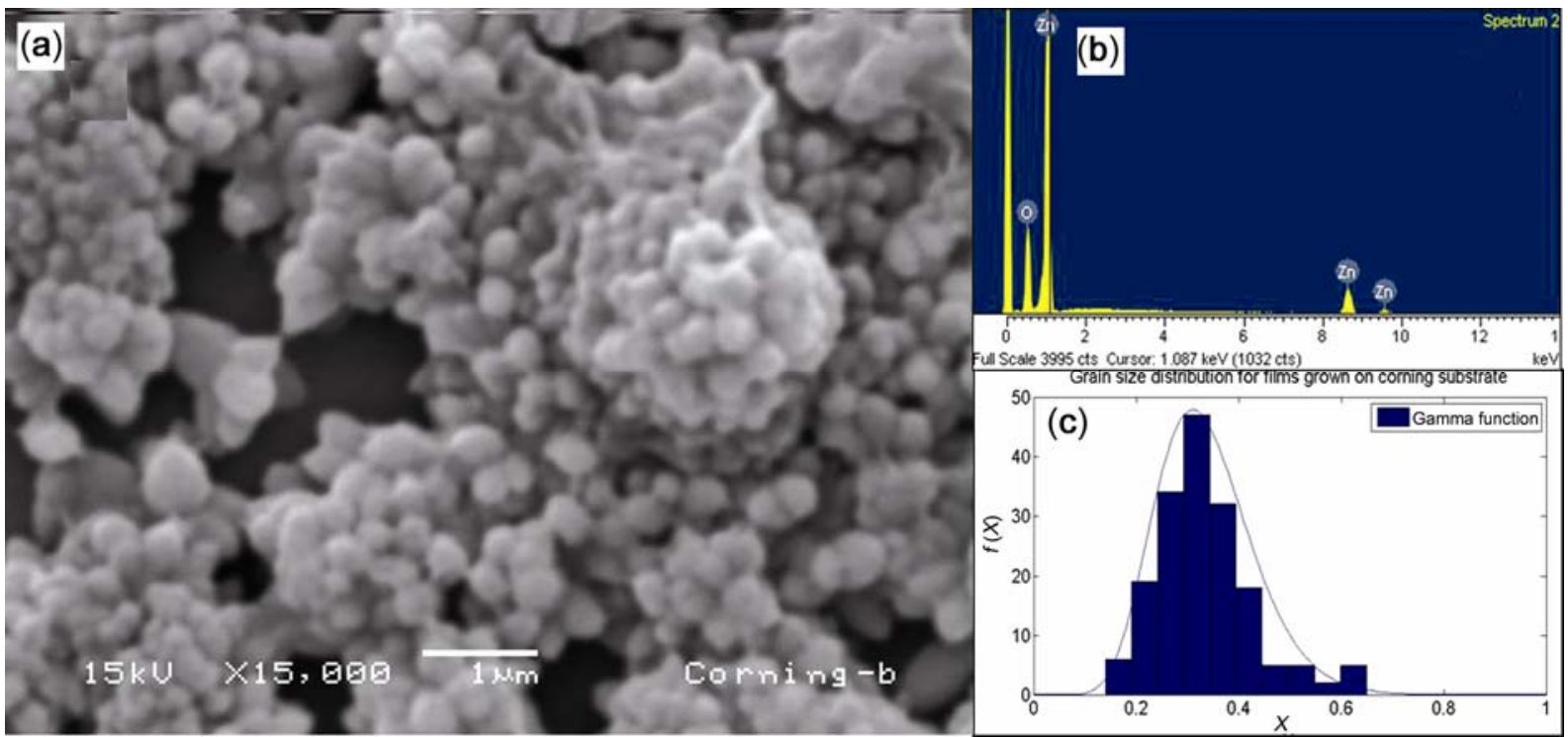

Figure 6. (a) Rice-like structure for films grown on corning glass substrate, (b) EDS spectrum for film grown on corning glass substrate and (c) histogram for the grain size distribution for film grown on corning glass substrate.

Table 2. Values obtained from EDS spectra for $\mathrm{ZnO}$ films grown on each substrate in one general region.

\begin{tabular}{|c|c|c|c|c|c|c|c|c|}
\hline \multirow[b]{2}{*}{ Substrates } & \multicolumn{2}{|c|}{ Glass } & \multicolumn{2}{|c|}{ Corning } & \multicolumn{2}{|c|}{ Quartz } & \multicolumn{2}{|c|}{$\mathrm{SiO}_{2}$} \\
\hline & Weight (\%) & Atomic (\%) & Weight (\%) & Atomic (\%) & Weight (\%) & Atomic (\%) & Weight (\%) & Atomic (\%) \\
\hline Zn L & 76.66 & $44 \cdot 57$ & $78 \cdot 38$ & $47 \cdot 01$ & $79 \cdot 12$ & $48 \cdot 11$ & $76 \cdot 32$ & $44 \cdot 10$ \\
\hline $\mathrm{O} \mathrm{K}$ & $23 \cdot 34$ & $55 \cdot 43$ & $21 \cdot 62$ & 52.99 & $20 \cdot 88$ & $51 \cdot 89$ & $23 \cdot 68$ & $55 \cdot 90$ \\
\hline
\end{tabular}

The histograms for grain distribution and their fitting curves are shown in figures 3(c)-6(c) for films grown on each substrate. The average grain sizes and its standard deviations were found for each film and those values are presented in table 1.

Results show that films grown on glass microslides substrate have the biggest values of crystallite and particle sizes. For corning substrate, both values (sizes of the grain and crystallite) were the smallest and a close view of SEM images also reveal that most $\mathrm{ZnO}$ particles are closely accumulated aggregation of smaller $\mathrm{ZnO}$ grains, which is consistent with the characteristics of nanoclusters. In addition to the rice-like structures, randomly distributed flower-like structures were also observed, as seen in figure 7(a)-(d) for each substrate. The formation of each flower-like structure might be due to the initial aggregation of several $\mathrm{ZnO}$ particles. An important point to be noted from figure 7 is the fact that the structure of each flower is not the same between substrates. Figure 7(a) shows a single flower, formed by small clusters of petals $50 \mathrm{~nm}$ in thickness. Other structures appear as ricelike branches interwoven each other (figure 7d), and the others like agglomeration of particles of different sizes (figure $7 \mathrm{~b}$ and $\mathrm{c}$ ). For the same substrate, there are also some differences: for example, in glass substrate, it was observed the formation of different kinds of flowers as rounded and leaves interwoven with each other, as seen in figure 7(a). For all the studied substrates, the morphology consists of the same structures (rice-like branches and flower-like structures).

All films grown on the different substrates have similar grain density; this is consistent with the wettability study, which did not show differences among the substrates. The formation of flower-like structure fits within crystallite sizes. Crystallites are bigger with regard to glass substrate that leads to the formation of better flowers. The same occurs with corning substrate. For quartz substrate and for $\mathrm{SiO}_{2}$, where the sizes of crystallites are smaller, flowers do not appear to be well defined. When crystallite sizes are bigger, the grown flowers are more and better defined.

There are some reports of flowers and spindle-like structure for $\mathrm{ZnO}$ films grown by the SILAR process (Suresh et al 2008) and by CBD (Chu et al 2009; Pawar et al 2010). Some other structures like nanorods, grown by spray pyrolysis on glass substrate (Nguyen et al 2009) and nanowires and nanoplates, grown by chemical vapour deposition (CVD) have been recently reported (Zhang et al 2009). The structures found suggest that the type of 

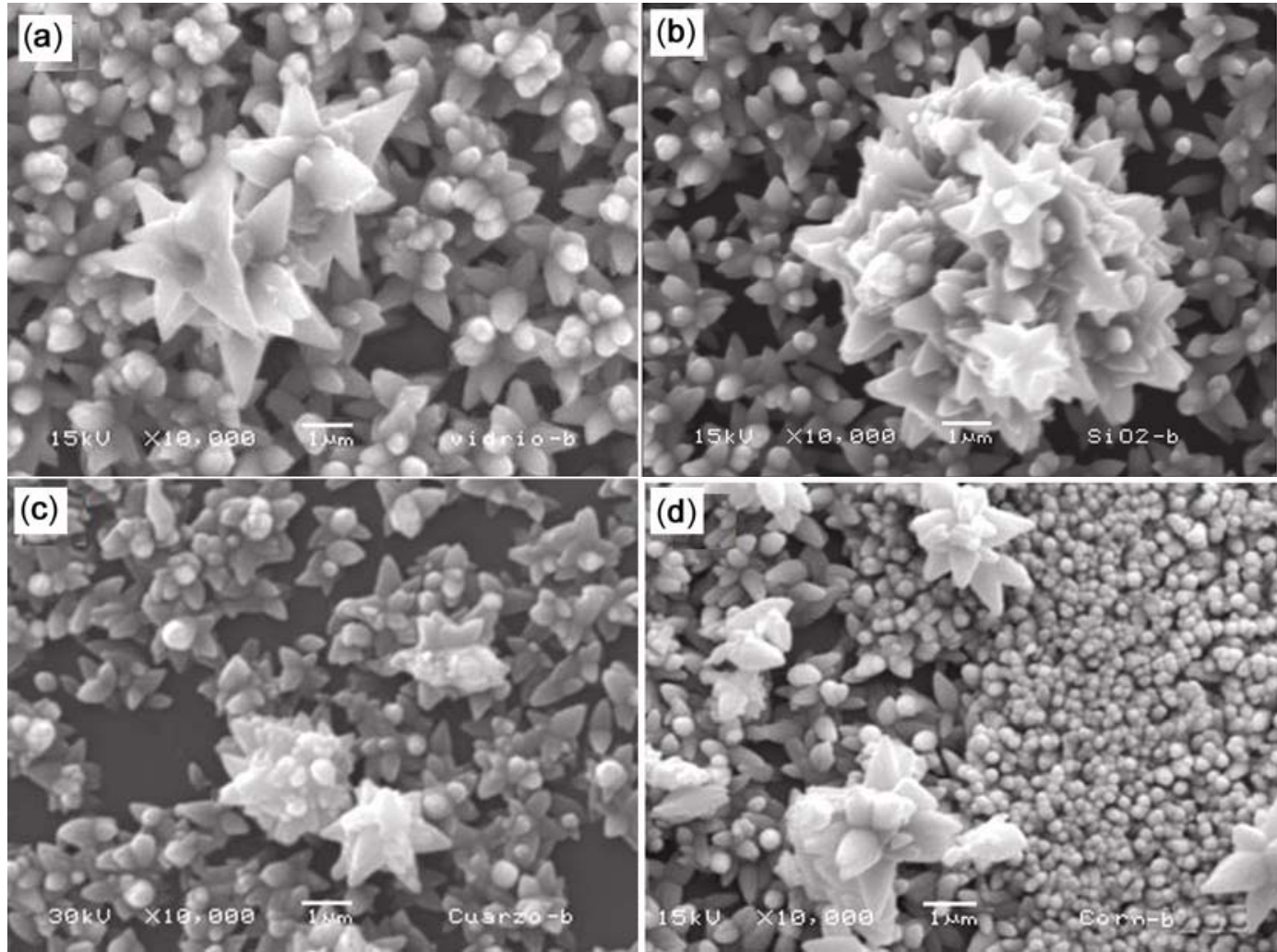

Figure 7. Flower-like structure for different substrates: (a) glass microslides, (b) $\mathrm{SiO}_{2}$, (c) quartz and (d) corning glass.

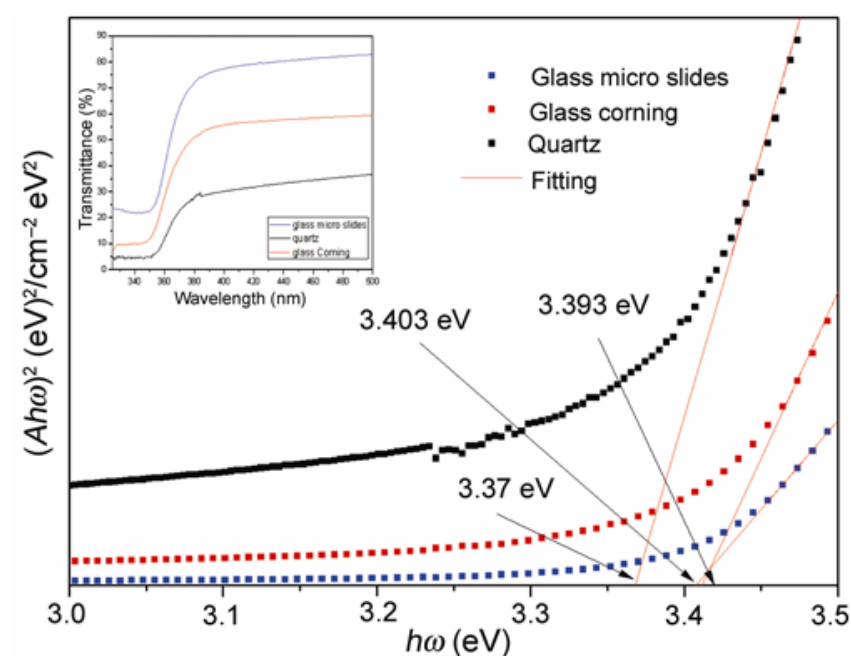

Figure 8. Transmittance pattern for $\mathrm{ZnO}$ films grown on substrates: (a) glass microslides, (b) corning glass and (c) quartz.

structure is more related to the process used to grow films than to the kind of the substrate employed.

\subsection{UV-Vis spectroscopy study}

Figure 8 shows the transmittance spectra for films grown on glass microslides, quartz and corning glass substrates, which were measured in wavelengths between 300 and $500 \mathrm{~nm}$. From these spectra, and taking into account that there is a direct allowed transition, the band gap energy $\left(E_{\mathrm{g}}\right)$ was obtained by extrapolating the linear dependence of $(A h \omega)^{2}$ vs $h \omega$ to the energy-axis intersection. Results show $E_{\mathrm{g}}$ values of $3.37,3.39$ and $3.40 \mathrm{eV}$ for samples grown on quartz, corning and microslides glass, respectively. These results are in agreement with those reported in the literature, between 3.3 and $3.4 \mathrm{eV}$ for $\mathrm{ZnO}$ films (Dutta et al 2009). These values are statistically equal because the uncertainty in measurements is approximately $0 \cdot 1 \mathrm{eV}$. The band gap energy shows no relation with the kind of employed substrate, and the microstrain in the interface does not affect the optical properties of the film.

\section{Conclusions}

$\mathrm{ZnO}$ films with hexagonal phase and wurtzite structure were obtained by the SILAR method on different substrates. The results obtained from XRD will help in concluding that the unit cell dimension for those films did not suffer significant modifications with respect to the used substrate, but the crystallite size, microstrain and TC values were influenced by the substrate. For the glass substrate, the crystallinity of films is better than those for the films grown on quartz and $\mathrm{Si}-\mathrm{SiO}_{2}$ substrates. This 
could be because the glass substrates have more amorphous characteristics and the films do not have to replicate some structure. The microstrain for films grown on glass microscope slide is higher than for the other substrates. Corning glass and quartz substrates have lower thermal expansion coefficient than the microscope glass slide, so that they suffer less thermal stress during the growing process, and the films grown on them exhibit less microstrain. According to the afore-mentioned information, microstrain could be generated by residual stress between substrates and films.

The morphology of the $\mathrm{ZnO}$ films was constituted by rice-like and flower-like structures and does not change significantly with the kind of substrate. Although there are some differences in grain sizes and the flowers forms, the basic structure is the same. These results suggest that the morphology is more related to the growing process than to the substrate. The band gap energy of films was independent from the used substrates.

\section{Acknowledgements}

This research project was financially supported by projects 120809 PAPIIT-UNAM and Conacyt 101032 Mexico. F N Jiménez-Garcia thanks Universidad Autónoma of Manizales for their support for the project 020026. The authors gratefully acknowledge Dra Beatriz Millán for her technical support. This paper was revised by translation center at the language institute of the Universidad Autónoma de Manizales.

\section{References}

Bach H and Krause D 2005 Low thermal expansion glass ceramics (New York: Springer Berlin Heidelberg) 2nd edn

Bai S N 2010 Optoelectron. Adv. Mater. 4654

Cao B Q et al 2007 Nanotechnology 18455707

Cerofolini G F et al 1997 J. Non-Cryst. Solids 216140
Cheng P et al 2008 Opt. Express 168896

Chu J B et al 2009 Appl. Phys. A95 849

Dutta S et al 2009 Prog. Mater. Sci. 5489

Egerton E et al 2005 J. Electron. Mater. 34949

Gao X D et al 2004 Appl. Surf. Sci. 229275

Hashimoto K et al 2005 Jpn. J. Appl. Phys. 1448269

Hermansson K et al 1991 Solid State Sensors Actuat. Int. Conf. 24193

Jiménez-García F N et al 2011 Thin Solid Films 5197638

Keis K et al 2002 Sol. Energy 7351

Kihara K and Donnay G 1985 Canad. Mineral. 23647

Kim T Y et al 2004 Synh. Metals 14461

Liang S et al 2001 J. Cryst. Growth 225110

Ljungberg K, Wderbarg A and Bklund Y 1993 Appl. Phys. Lett. 6222

Lokhande C D 2003 Solar Mater. Solar Cells 79293

Mittemeijer E and Welzel U 2008 Kristallogr. 223552

Mitra P et al 1998 Mater. Lett. 3533

Mitra P and Khan J 2006 Mater. Chem. Phys.98 279

Moholkar A V et al 2007 J. Phys. Chem. Solids 681981

Nguyen T et al 2009 Phys. Eng. New Mater. 127177

Ortega-López M et al 2003 Mater. Res. Bull. 381241

Pathan H M and Lokhande C D 2004 Bull. Mater. Sci. 2785

Pawar S M et al 2010 J. Nanosci. Nanotechnol. 103412

Pawar S M et al 2011 Curr. Appl. Phys. 11117

Pizzini N et al 1989 J. Electrochem. Soc. 1361945

Rambu A P et al 2012 Mater. Sci. Eng. B177 157

Robert E Dinnebier and Simon J L Billinge 2008 Powder diffraction theory and practice (Cambridge: RSC Publishing)

Saito N 2002 Adv. Mater. 14418

Shan F K et al 2004 J. Eur. Ceram. Soc. 241015

Shen G et al 2005 J. Phys. Chem. B109 10578

Shinde V R et al 2005 Appl. Surf. Sci. 245407

Sillen L G and Martell A F (eds) 1971 Stability constant of metal ion complexes (London: The Chemical Society), Special Publication No. 25, Suppl. 1

Srivastava R et al 2007 Sens. Trans. J. 801295

Suresh P et al 2008 Appl. Surf. Sci. 2552382

Vargas-Hernández V et al 2008 Microelectr. J. 391347

Vargas-Hernández V 2008 Microelectr. J. 391349

Villanueva Y Y et al 2006 Thin Solid Films 501366

Zhang N et al 2009 Mater. Lett. 63496 